\title{
Effect of Nano-Scale Copper Sulfide Precipitation on Mechanical Properties and Microstructure of Rapidly Solidified Steel with Tramp Copper Element
}

\author{
Zhongzhu Liu ${ }^{1}$, Yoshinao Kobayashi ${ }^{2}$, Jian Yang ${ }^{1}$, Kotobu Nagai ${ }^{2}$ and Mamoru Kuwabara ${ }^{1}$ \\ ${ }^{1}$ Graduate School of Engineering, Nagoya University, Nagoya 464-8603, Japan \\ ${ }^{2}$ National Institute for Materials Science, Tsukuba 305-0047, Japan
}

\begin{abstract}
Copper is one of the main residual elements in steel, especially in recycled scrap steel, whereas sulfur is one of the main impurities in steel. A large quantity of slag and $\mathrm{CO}_{2}$ is produced during the process of removing the sulfur from the steel. However, copper and sulfur may combine to form copper sulfide, especially during the rapid cooling process. In this paper samples containing and not containing fine copper sulfide are prepared by the rapid solidification process. The microstructure, sulfide precipitates, and the mechanical properties of the samples are investigated by optical microscopy, Scanning Electron Microscope (SEM), Transmission Electron Microscopy (TEM), and the tensile testing. A large difference in the yield strength between the samples containing and not containing copper sulfides is observed. Each contribution of solid solution strengthening, grain refining strengthening, and sulfide precipitates strengthening in the samples with and without copper sulfide has been discussed. Particular attention has been paid to effect of the nano-scale copper sulfides, that is, main factor contributing to the alloy strengthening. Contribution of reduction of the copper sulfide particle size has also been discussed by comparing the results of two rapid solidification processes with different cooling rates. [doi:10.2320/matertrans.47.2312]
\end{abstract}

(Received February 20, 2006; Accepted July 24, 2006; Published September 15, 2006)

Keywords: copper sulfide, precipitation, rapid solidification, low carbon steel

\section{Introduction}

Copper is one of the major residual elements in steel because it is difficult to remove during the steelmaking process. The concentration of copper in steel has been increasing gradually due to the continuous recycling of scrap steel. Copper may cause hot shortness at high temperatures since it is harder to be oxidized than the iron matrix. However, it could be used as an alloying element in some steels to improve the corrosion resistance and to enhance the mechanical properties. ${ }^{1-3)}$

Sulfur is an undesirable impurity in steel since it may lead to low toughness and poor weldability. Sulfides in steel also cause problems due to their size and morphology. Large sulfides usually result in bad mechanical properties, and nonspherical sulfides cause some properties with anisotropy. However, the removal of sulfur from steel results in a large quantity of slag and $\mathrm{CO}_{2}$ exhaust.

A lot of attention has been given to the strengthening effects from the copper solid solution or the copper particle precipitates in steel. ${ }^{1-3)}$ However, copper and sulfur in steel may form copper sulfide on a nano-scale size, especially during the rapid solidification/cooling process. ${ }^{4,5)}$ These nano-scale copper sulfides may also increase the strength and work hardening ability of steel. In a previous paper, ${ }^{5)}$ the present authors have investigated the microstructure, sulfide precipitates, and the tensile test properties of an as-cast (strip casting) sample and an annealed sample. Nano-scale copper sulfide that were found in the as-cast samples contributed the most to the difference in the yield strength between the ascast and the annealed samples. However, the as-cast and the annealed samples had very different microstructure. Therefore, it may not be appropriate to use the same criterion for the as-cast sample and the annealed sample when estimating the contribution of the copper sulfide to the yield strength and strain hardening ability.

In this paper, two as-cast samples, one with copper sulfide and the other without copper sulfide, are prepared by the rapid solidification process in the laboratory to make sure that they have almost the same microstructures. The microstructures, sulfide precipitates, and the mechanical properties are investigated to understand the copper sulfide precipitation during the rapid solidification process and the precipitates' contribution to the yield strength and strain hardening ability. In addition, the factors affecting the size of the copper sulfide are discussed by comparing the results of the laboratory $\mathrm{Cu}$ mould casting process with those of the strip casting process.

\section{Experimental Procedures}

\subsection{Materials and casting conditions}

The chemical compositions for four kinds of steel samples, which are designated as $8 \mathrm{Cu} 0 \mathrm{~S}$ and $8 \mathrm{Cu} 1 \mathrm{~S}$ as well as $\mathrm{AC}$ and HA steel, are shown in Table $1.8 \mathrm{Cu} 0 \mathrm{~S}$ and $8 \mathrm{Cu} 1 \mathrm{~S}$ samples are prepared in an induction heating furnace under vacuum atmosphere in the laboratory. After $3 \mathrm{~kg}$ of electrolytic iron is melted, the alloying elements ( $\mathrm{Mn}, \mathrm{Si}, \mathrm{Cu}, \mathrm{S})$ are added to the melted iron. The melt is then cast into a water cooled copper mould. A specimen with a $3 \times 60 \times 200 \mathrm{~mm}$ steel plate on one side and a $5 \times 60 \times 200 \mathrm{~mm}$ steel plate on the other side can be obtained as shown in Fig. 1. Hereafter, this casting process is named as $\mathrm{Cu}$ mould casting process and only the plates with the $3 \mathrm{~mm}$ thickness are discussed in the paper. As shown in Fig. 1(b), a set of temperatures is measured at the center of the point on the $3 \mathrm{~mm}$ thickness plate during the casting process. AC sample is a strip casting sample produced by a twin drum caster at the Mitsubishi Heavy

Table 1 The chemical composition of the samples, mass $\%$.

\begin{tabular}{ccccccccr}
\hline Sample & $\mathrm{C}$ & $\mathrm{Si}$ & $\mathrm{Mn}$ & $\mathrm{P}$ & $\mathrm{S}$ & $\mathrm{Cu}$ & $\mathrm{Al}_{\mathrm{T}}$ & thickness \\
\hline 8Cu0S & 0.072 & 0.17 & 0.68 & 0.016 & 0.0023 & 0.085 & 0.004 & $3 \mathrm{~mm}$ \\
8Cu1S & 0.075 & 0.16 & 0.68 & 0.019 & 0.0132 & 0.086 & 0.003 & $3 \mathrm{~mm}$ \\
AC/HA & 0.08 & 0.05 & 0.54 & 0.12 & 0.010 & 0.07 & 0.01 & $3.6 \mathrm{~mm}$ \\
\hline
\end{tabular}



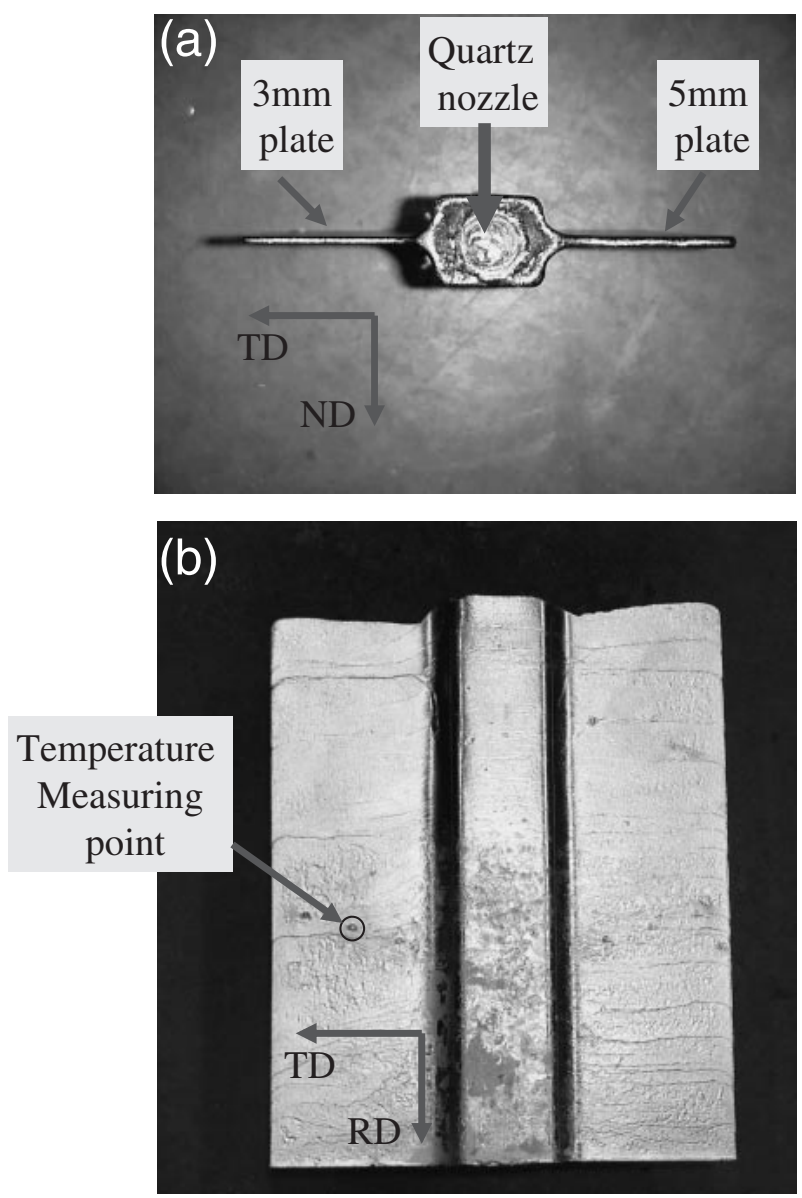

Fig. 1 As-cast samples produced by lab rapid solidification process.

Industries Ltd., Hiroshima R\&D Center. The casting speed is $0.333 \mathrm{~m} / \mathrm{s}$, the casting temperature is about $1846 \mathrm{~K}$, the casting weight is $200 \mathrm{~kg}$, and the mold width is $600 \mathrm{~mm}$. One type of post-treatment, homogenization annealing, is applied to the AC sample to homogenize the microstructure in the fluid argon atmosphere for $1.08 \times 10^{4} \mathrm{~s}$ at $1473 \mathrm{~K}$ and then furnace cooled to room temperature. Hereafter the treated strip is called the HA sample. More detail description of the preparation of $\mathrm{AC}$ and HA samples could be found in a previous paper. ${ }^{5)}$

\subsection{Analysis methods}

The microstructure, grain size distribution and the precipitates are investigated on the section of $1 / 4$ thickness of sample by optical microscopy, SEM and TEM. Samples are etched with 3 vol\% nitric acid (Nital) to reveal their microstructures. The grain size distribution is performed on a LEO 1550 SEM coupled with an orientation image microscopy (OIM) electron backscattering diffraction technique (EBSD) system after the sample is electrochemically polished. Carbon extraction replicas are prepared through the standard procedures for TEM observation. The replicas are floated on molybdenum grids, and a beryllium specimen holder is used to avoid a possible detection of $\mathrm{Cu}$ from the grid and the specimen holder. The TEM observation is performed on a JEM-2000FXII microscope operated at $200 \mathrm{kV}$ and coupled to an Energy Dispersive X-Ray Spectroscopy (EDS).

The tensile properties of the samples in the Transverse Direction (TD) are measured with a Shimadzu AG-50KNG universal test machine at a strain rate of $2.5 \times 10^{-4} \mathrm{~s}^{-1}$ at ambient temperature. The gage section of these tensile specimens has a width of $8 \mathrm{~mm}$, a length of $25 \mathrm{~mm}$, and a thickness of $2.6 \mathrm{~mm}$ for $8 \mathrm{Cu} 0 \mathrm{~S}$ and $8 \mathrm{Cu} 1 \mathrm{~S}$ samples while $10 \mathrm{~mm}$ (width), $30 \mathrm{~mm}$ (length) and $3.2 \mathrm{~mm}$ (thickness) for $\mathrm{AC}$ and HA samples. Four specimens are tested for each sample and the tensile properties are determined by the displacement-load curves. The displacement is measured by an extensometer. All the initial displacements to about $10 \%$ were successfully acquired although the full range of displacement could not always be obtained for all the specimens. Therefore the analysis of the strain-hardening rate for strains up to about $10 \%$ is performed for all the specimens on the displacement-load curves.

\section{Experimental Results and Discussion}

\subsection{Dendrite structure and cooling history}

Figure 2 shows the dendrite structure in the longitudinal section of the $\mathrm{AC}, 8 \mathrm{Cu} 0 \mathrm{~S}$ and $8 \mathrm{Cu} 1 \mathrm{~S}$ samples. Dendrites are well developed almost throughout the thickness regardless of the chemical composition of samples. Equiaxed crystals are seldom observed except for the surface layer and few central regions in the $8 \mathrm{Cu} 0 \mathrm{~S}$ and $8 \mathrm{Cu} 1 \mathrm{~S}$ samples; while in the $\mathrm{AC}$ sample a thin layer of equiaxed crystals is observed in the central regions.

The primary dendrite arm spacing, $d_{I}$, is about $55 \mu \mathrm{m}$, and the secondary dendrite arm spacing, $d_{I I}$, is about (18-28) $\mu \mathrm{m}$ in both the $8 \mathrm{Cu} 0 \mathrm{~S}$ and $8 \mathrm{Cu} 1 \mathrm{~S}$ samples. These data are about $40 \mu \mathrm{m}$ and (12-25) $\mu \mathrm{m}$, respectively in AC sample. The secondary dendrite arm spacing of the conventional slab is about (100-200) $\mu \mathrm{m}$ while (10-20) $\mu \mathrm{m}$ for $2.2 \mathrm{~mm}$ thick strip
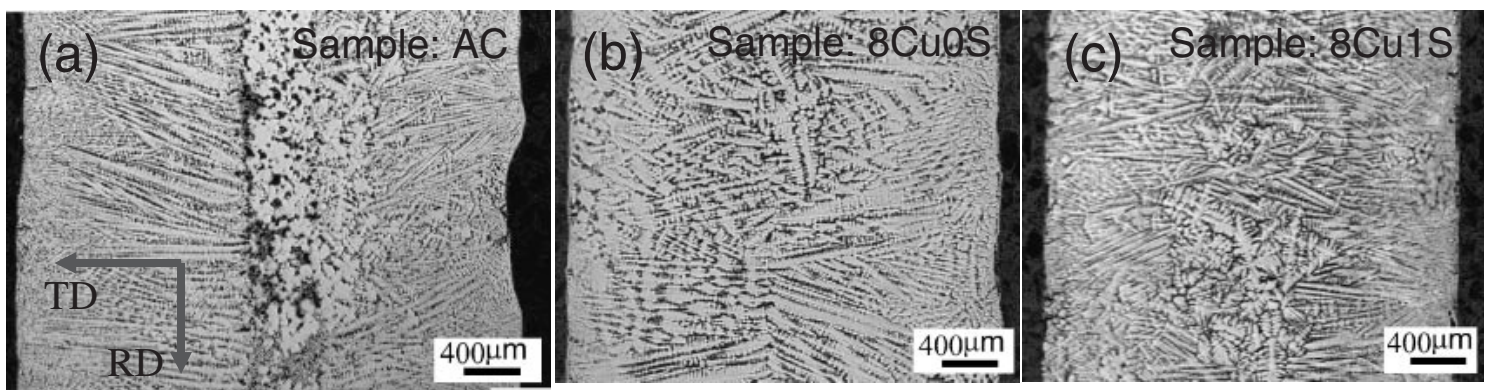

Fig. 2 Dendrite structure in the longitudinal section of the AC (a), 8Cu0S (b) and 8Cu1S (c) samples. 

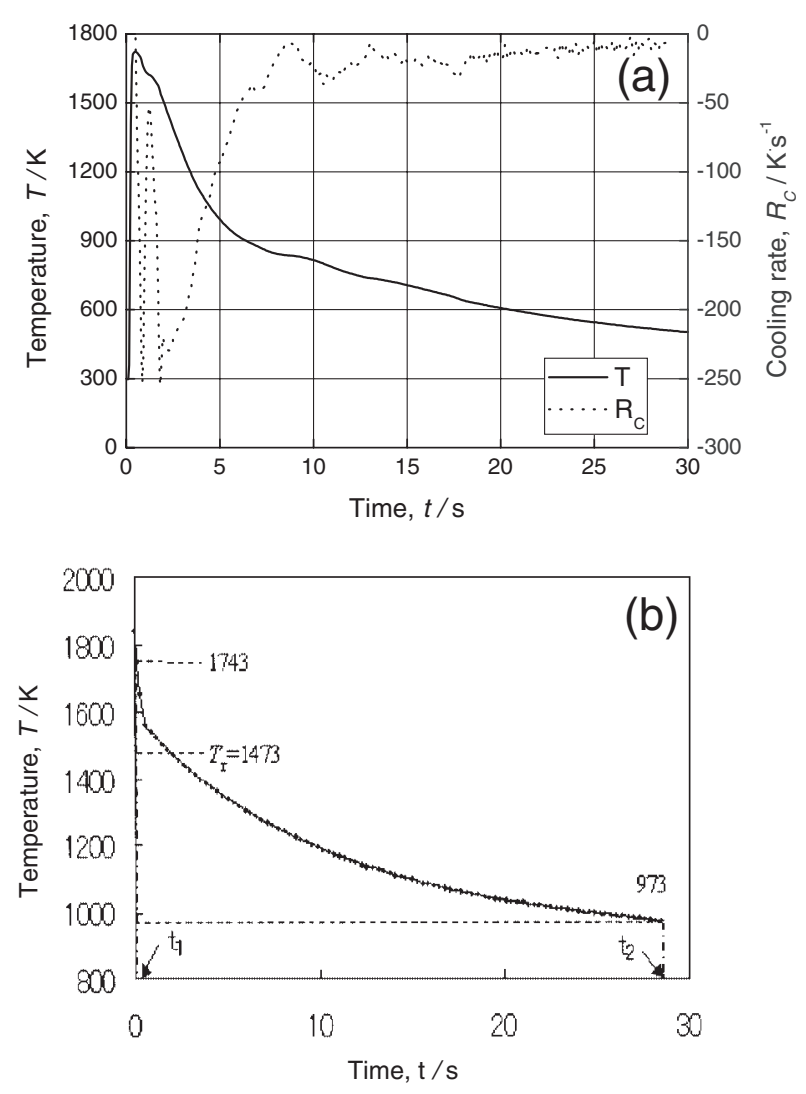

Fig. 3 Measured temperature history for the $8 \mathrm{Cu} 1 \mathrm{~S}$ sample (a) and the estimated temperature history for strip casting $0.1 \mathrm{C}-0.15 \mathrm{Si}-0.60 \mathrm{Mn}-0.2 \mathrm{P}$ steel (b).

casting steels. $\left.{ }^{6}\right)$ The secondary dendrite arm spacing in the $8 \mathrm{Cu} 0 \mathrm{~S}$ and $8 \mathrm{Cu} 1 \mathrm{~S}$ samples are far less than that of the conventional slab while a little larger than that of the strip casting of 2 or $3 \mathrm{~mm}$ thick samples. The cooling rate on the solidification of the $8 \mathrm{Cu} 0 \mathrm{~S}$ and $8 \mathrm{Cu} 1 \mathrm{~S}$ samples could be estimated as about $250 \mathrm{~K} / \mathrm{s}$ from the second dendrite arm spacing based on the following equation, ${ }^{7)}$ where $R$ is the cooling rate on the solidification in $\mathrm{K} / \mathrm{s}$. For the $\mathrm{AC}$ sample, the cooling rate on solidification is about $600 \mathrm{~K} / \mathrm{s}$.

$$
d_{I I}=688(60 \times R)^{-0.36}, \mu \mathrm{m}
$$

The cooling rates on solidification of the $8 \mathrm{Cu} 1 \mathrm{~S}$ and $8 \mathrm{Cu} 0 \mathrm{~S}$ samples are about 100 times larger than that of the conventional slab while only one third of that of the AC sample. Figure 3(a) shows the measured temperature history of the $8 \mathrm{Cu} 1 \mathrm{~S}$ sample during casting. For comparison, Figure 3(b) shows the estimated continuous cooling curve from liquids to $973 \mathrm{~K}$ for a $0.1 \mathrm{C}-0.15 \mathrm{Si}-0.60 \mathrm{Mn}-0.20 \mathrm{P}$ (in mass) strip casting steel (strip thickness $2.2 \mathrm{~mm}$ ) by Hirata, ${ }^{6}$ which was cast by the same twin drum caster as the AC sample. The cooling history of the AC sample may be roughly estimated from that curve. For the $8 \mathrm{Cu} 1 \mathrm{~S}$ sample, it was obvious that the first cooling rate, hereafter means the cooling rate on solidification, was lower than that during strip casting process; while the second cooling rate, hereafter means the cooling rate after solidification, was higher than that during strip casting process. For example, the temperature of the $8 \mathrm{Cu} 1 \mathrm{~S}$ sample at 28 seconds after casting is about $500 \mathrm{~K}$ while it is about $970 \mathrm{~K}$ in strip casting process. After casting, the $8 \mathrm{Cu} 1 \mathrm{~S}$ and $8 \mathrm{Cu} 0 \mathrm{~S}$ samples were still cooled by the water-cooled mould until ambient temperature; while the sample produced by strip casting process was radiantly cooled on the transportation rollers table. That results in the different cooling history after solidification for the above two casting process.

There are two retarded periods on the temperature curves in Fig. 3(a). These periods correspond to the two large antipeaks on the cooling rate curve as shown in Fig. 3(a). They also correspond to the $\delta \rightarrow \gamma$ and $\gamma \rightarrow \alpha$ phase transformation, respectively. If we estimate the equilibrium phase transformation temperature by the following equations, ${ }^{8,9)}$ the undercooling degrees to the $\delta \rightarrow \gamma$ and $\gamma \rightarrow \alpha$ phase transformation are about 70 and $370 \mathrm{~K}$, respectively, for the $\mathrm{Cu}$ mould casting process.

$$
\begin{aligned}
\mathrm{T}_{\mathrm{A} 4}= & 1665+1122[\% \mathrm{C}]-60[\% \mathrm{Si}] \\
& +12[\% \mathrm{Mn}]-550[\% \mathrm{P}]-160[\% \mathrm{~S}], \mathrm{K} \\
\mathrm{T}_{\mathrm{A} 3}= & 1183-203[\% \mathrm{C}]^{0.5}+44.7[\% \mathrm{Si}]-30[\% \mathrm{Mn}] \\
& +700[\% \mathrm{P}]-20[\% \mathrm{Cu}], \mathrm{K}
\end{aligned}
$$

From the above analysis, we can see that the first and the second cooling rates for the $\mathrm{Cu}$ mould casting process and the strip casting process are quite different. The first cooling rate of the $\mathrm{Cu}$ mould casting process is somewhat lower than that of the strip casting process; while the second cooling rate is much higher than that of the strip casting process. These differences cause some discrepancy in the size of the copper sulfide and the ferrite grain, which will be discussed in later sections.

\subsection{Ferrite structure}

Figure 4 represents the microstructures of the AC and HA strips. Both of acicular ferrites and irregular polygonal ferrites are detected in the AC strip. Through the homogenization annealing, the irregular and acicular ferrites are converted into a more regular polygonal structure, as shown in Figure 4(b). The difference in the structure is difficult to evaluate using only the optical microscopy photos. Thus, the OIM analysis coupled to SEM is conducted to measure the size distribution of these samples. ${ }^{10)}$ The grain boundaries in the polished surface are determined by spatial misorientations of more than $5^{\circ}$ between two probed points. The grain area is transformed into a grain diameter by the cycle-shape approximation. The mean diameters of ferrite grains in the $\mathrm{AC}$ and the HA strips were measured as 62.6 and $98.2 \mu \mathrm{m}$, respectively.

Figure 5 shows the ferrite structure of the $8 \mathrm{CuOS}$ and $8 \mathrm{Cu} 1 \mathrm{~S}$ samples taken by optical microscopy. Both the acicular ferrites and irregular polygonal ferrites are observed in both samples. These structures are similar with those in AC sample. The structures in the $8 \mathrm{Cu} 1 \mathrm{~S}$ and $8 \mathrm{Cu} 0 \mathrm{~S}$ samples obviously belong to the same category and it is possible and reasonable to use the same criterion to estimate their contribution to the tensile properties. Figure 6 shows the ferrite structure that was developed by the OIM analysis. Figure 7 shows the distribution of the measured grain area and the grain number in the $8 \mathrm{Cu} 0 \mathrm{~S}$ and $8 \mathrm{Cu} 1 \mathrm{~S}$ samples. The distributions of the grain area and the grain number in both samples are similar, for example the diameters of most of the 

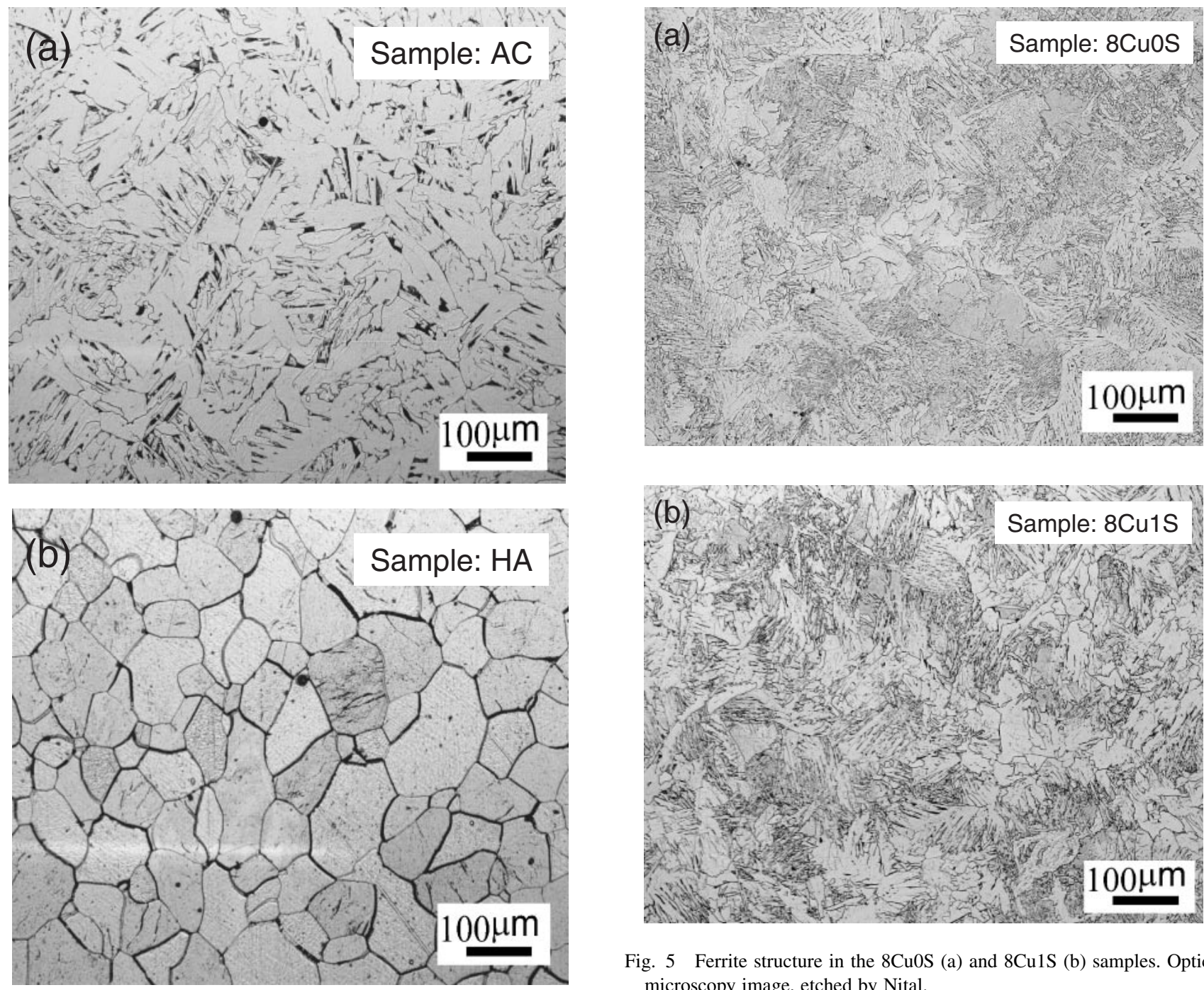

Fig. 5 Ferrite structure in the $8 \mathrm{Cu} 0 \mathrm{~S}$ (a) and $8 \mathrm{Cu} 1 \mathrm{~S}$ (b) samples. Optical microscopy image, etched by Nital.

Fig. 4 Microstructure of (a) AC sample and (b) HA sample.

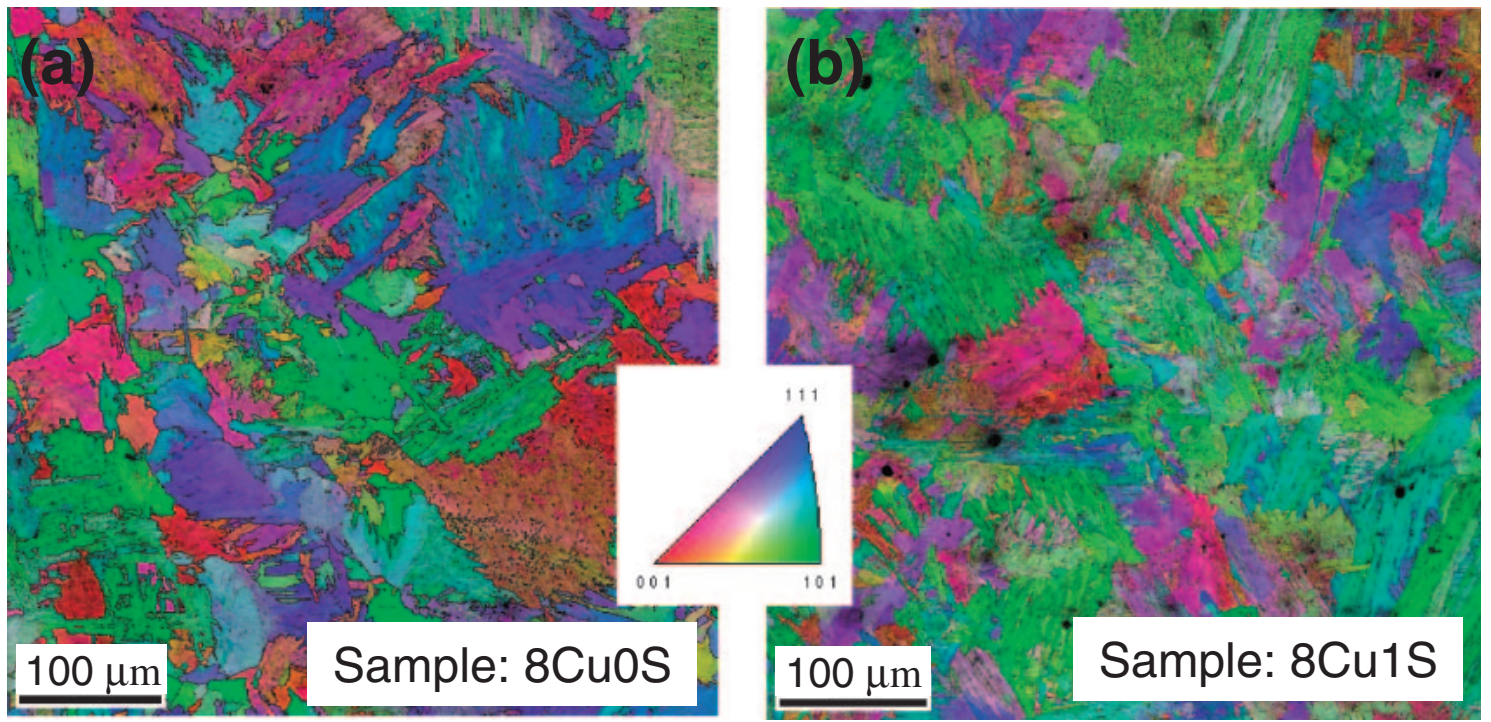

Fig. 6 Ferrite structure that was developed after the OIM analysis.

grains (more than 90\%) in both samples are less than $10 \mu \mathrm{m}$. However, the fraction of small size grains in the $8 \mathrm{Cu} 1 \mathrm{~S}$ sample is slightly higher than that in the $8 \mathrm{Cu} 0 \mathrm{~S}$ sample; while the fraction of large size grains is the opposite. The measured mean diameters of the ferrite grains in the $8 \mathrm{Cu} 1 \mathrm{~S}$ and $8 \mathrm{Cu} 0 \mathrm{~S}$ samples are 38.48 and $50.97 \mu \mathrm{m}$, respectively. These data are 

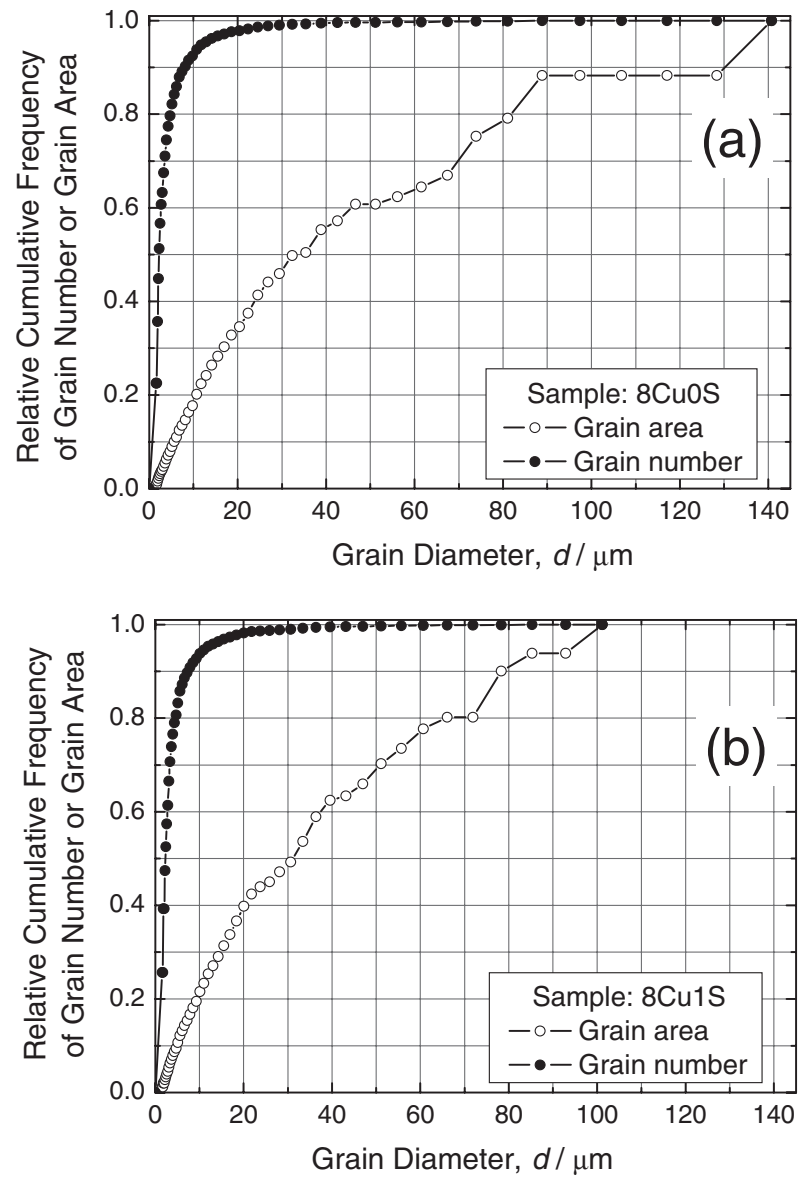

Fig. 7 The distribution of grain area and size analyzed by OIM.

a little smaller than those in the AC and HA samples, which were believed due to the higher second cooling rates of the $\mathrm{Cu}$ mould casting process compared with the strip casting process.

Although the $8 \mathrm{Cu} 1 \mathrm{~S}$ and the $8 \mathrm{Cu} 0 \mathrm{~S}$ samples show similar temperature history, the ferrite grain size in the $8 \mathrm{Cu} 1 \mathrm{~S}$ sample is somewhat smaller than that in the $8 \mathrm{Cu} 0 \mathrm{~S}$ sample. It may have been caused by the fine copper sulfide particles existing in the $8 \mathrm{Cu} 1 \mathrm{~S}$ sample and will be discussed later.

\subsection{Second phase precipitates}

A lot of tiny particles are observed in $8 \mathrm{Cu} 1 \mathrm{~S}$ sample as shown in Fig. 8. These particles are less than $50 \mathrm{~nm}$ and the EDS analysis shows the main composition of these particles are $\mathrm{Cu}$ and $\mathrm{S}$ including a little $\mathrm{Mn}$ and $\mathrm{Fe}$. The mean size of these tiny copper sulfide particles is about $34 \mathrm{~nm}$. Some larger size sulfide particles are also observed in the $8 \mathrm{Cu} 1 \mathrm{~S}$ sample. The concentration of $\mathrm{Mn}$ in sulfide particles increases with particle's size increasing while that of $\mathrm{Cu}$ decreases as shown in Fig. 9. The sulfides with largest size and high Mn concentration are speculated to precipitate at high temperature such as on or just after solidification.

A lot of the tiny copper sulfides are also observed in the AC sample as shown in Fig. 10. These sulfides are with a size of less than $50 \mathrm{~nm}$ and are composed of mainly $\mathrm{Cu}$ and $\mathrm{S}$ including a little Fe (Fig. 10(b)). The mean size is about $15 \mathrm{~nm}$. In the AC strip, sulfide particle with a size of larger than $100 \mathrm{~nm}$ is also observed which is usually a type of (Mn,
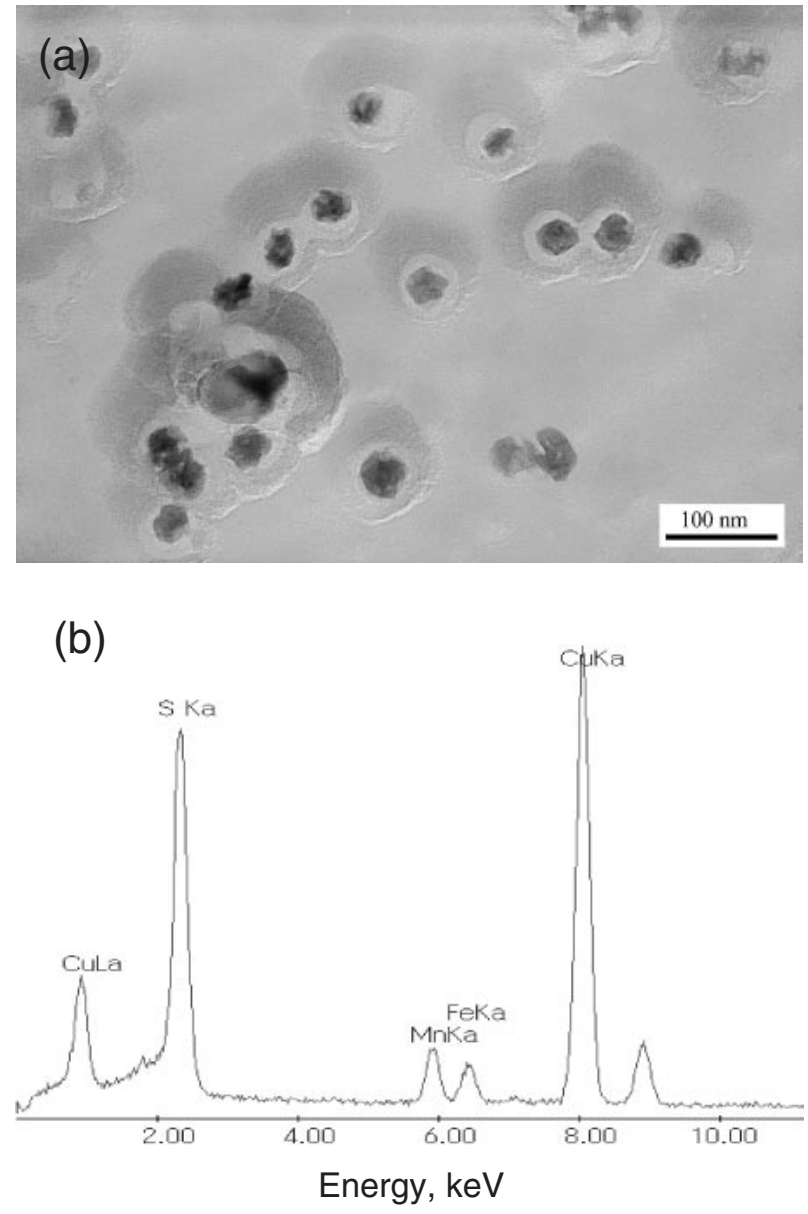

Fig. 8 Morphology and size of copper sulfides in the 8Cu1S sample. (a) TEM image, extraction replica specimen; (b) EDS spectrum.

$\mathrm{Cu}, \mathrm{Fe}) \mathrm{S}$. In the HA strip, the sulfides are grown up and the number of sulfides decreases as clearly shown in Fig. 11. The sulfides in HA sample are about (100-800) $\mathrm{nm}$ in size and their compositions are mainly $\mathrm{MnS}$.

In the AC sample the copper sulfide had smaller size than those in the $8 \mathrm{Cu} 1 \mathrm{~S}$ sample. Lower precipitating temperature and higher super-saturation on precipitating could result in finer size particles. In previous papers, ${ }^{5,11-13)}$ the present authors have discussed the effects of the following factors on copper sulfide precipitation in steel: the slope of the solubility curve, the orientation relationship between copper sulfide and matrix, the chemical composition of steel especially the concentration of phosphorus in steel. Copper sulfide is easier to obtain higher super-saturation compared with manganese sulfide at the same cooling rate. This is due to the quite sharper solubility curve of copper sulfide compared with that of manganese sulfide. The sharp solubility curve results in large solubility of $\mathrm{Cu}$ and $\mathrm{S}$ in steel at high temperature, such as on and just after solidification; while low solubility of $\mathrm{Cu}$ and $\mathrm{S}$ in steel at low temperature, such as in $\alpha$-Fe region. The coherent relationship between $\mathrm{Cu}_{2} \mathrm{~S}$ and $\alpha$-Fe greatly decreases the critical activation energy for nucleation and increases the nucleation rate when $\mathrm{Cu}_{2} \mathrm{~S}$ precipitates from $\alpha$-Fe phase. Then $\mathrm{MnS}$ has an advantage to precipitate at high temperature range, while the precipitation of $\mathrm{Cu}_{2} \mathrm{~S}$ is dominant at low temperature range, especially from $\alpha$-Fe phase. 

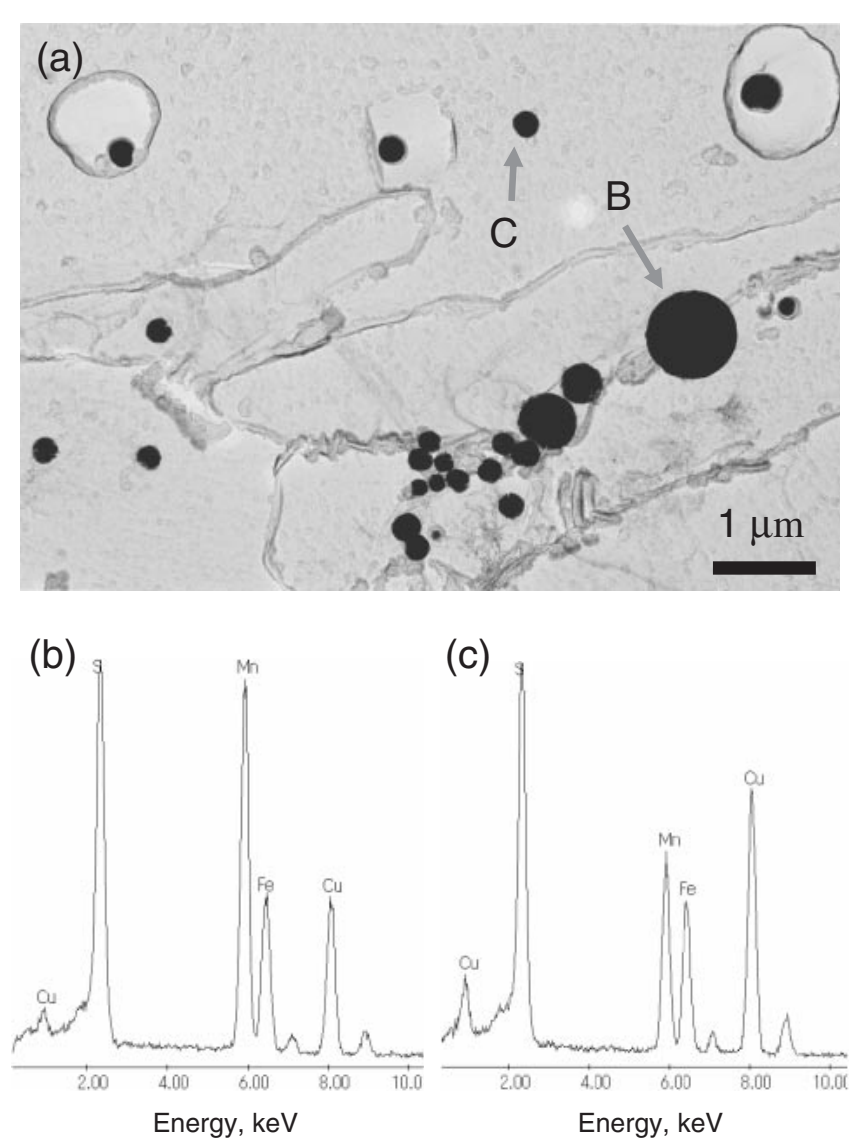

Fig. 9 Morphology and size of large sulfides in the 8Cu1S sample. (a) TEM image, extraction replica specimen; EDS spectrum of (b) point B and (c) point $\mathrm{C}$.

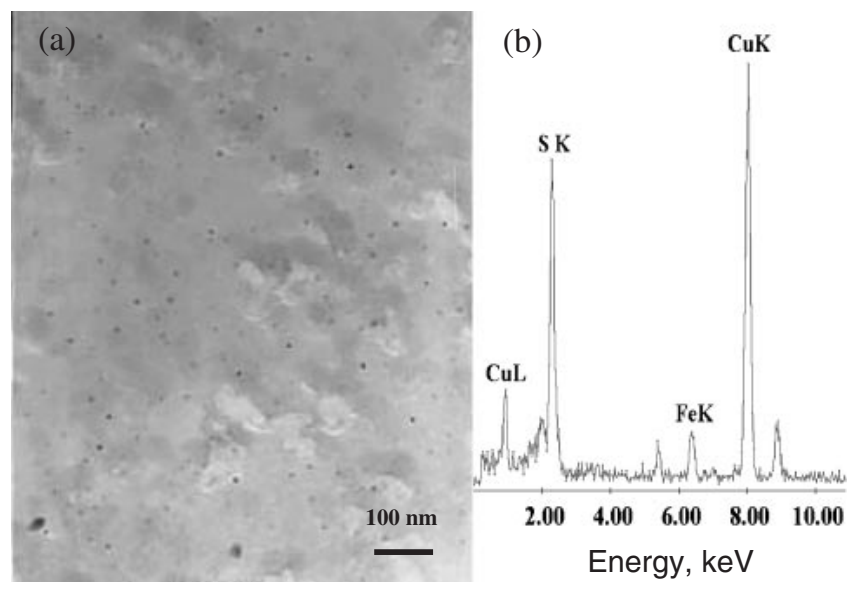

Fig. 10 TEM image (extraction replica specimen) (a) and EDS spectrum (b) of fine copper sulfide in AC sample.

Phosphorus has greatly effects on the phase transformation temperature and process. Phosphorus could quietly decrease the solidus temperature as well as the transformation temperature from $\delta$-Fe to $\gamma$-Fe. MnS usually precipitates at the last stage of solidification due to micro-segregation of $\mathrm{S}$ and $\mathrm{Mn}$ elements. In addition, MnS has larger solubility in $\delta$-Fe compared with in $\gamma$-Fe. Then phosphorus could suppress the $\mathrm{MnS}$ precipitation at the last stage of solidification and during the $\delta / \gamma$ transformation. That means the precipitation
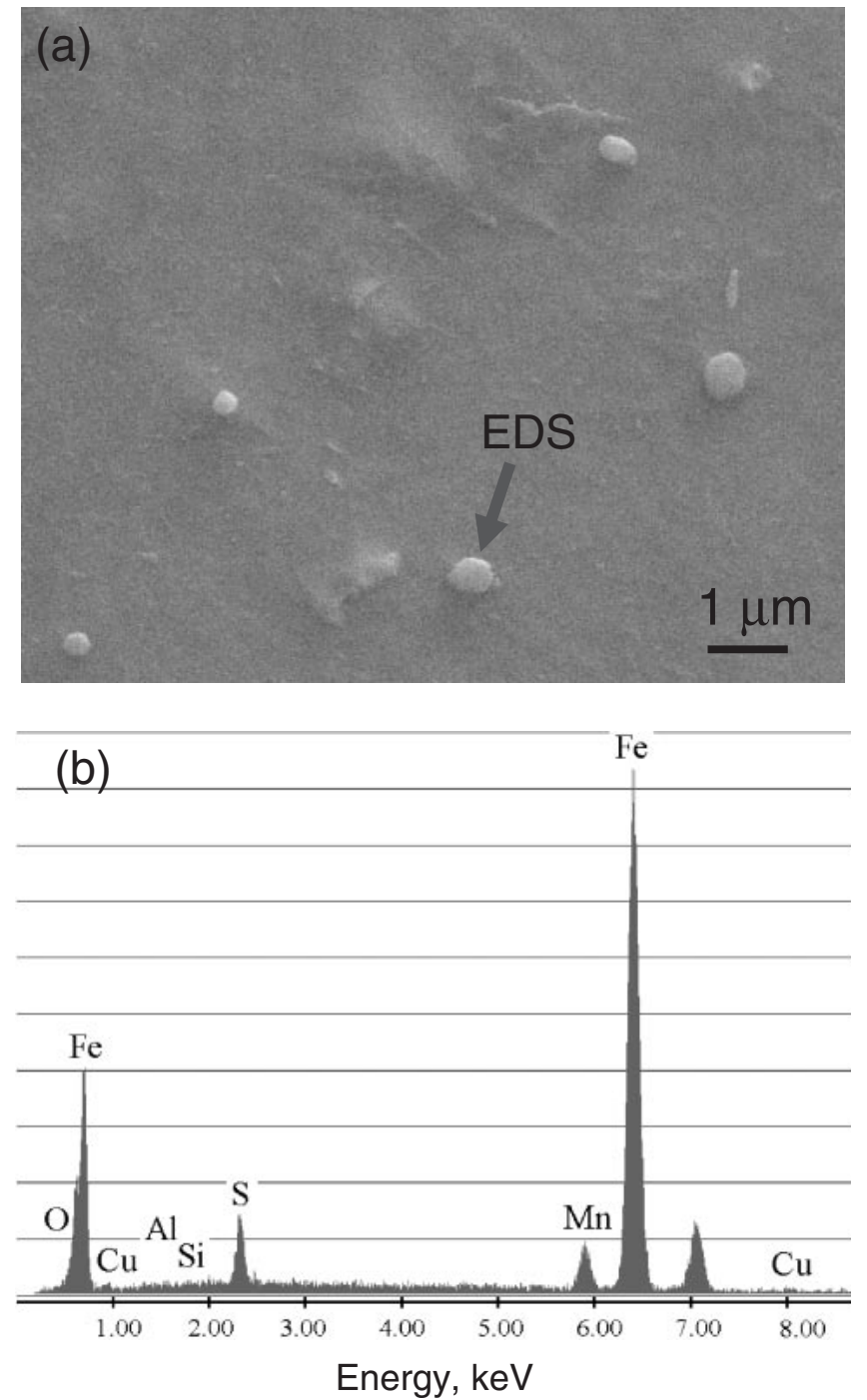

Fig. 11 SEM image (a) and EDS spectrum (b) of sulfide precipitates in HA sample.

of $\mathrm{MnS}$ at high temperature is retarded to lower temperature range. On the other hand, phosphorus could increase the $\gamma / \alpha$ transformation temperature. Then more sulfides could precipitate from $\alpha$-Fe instead of from $\gamma$-Fe in steel containing high phosphorus, especially during rapid cooling process, at which the $\mathrm{MnS}$ precipitation at high temperature is also suppressed by the high cooling rate to some extend. Since AC sample contains high phosphorus while there are no such effects from solutes such as phosphorus in the 8Cu1S sample, this may be one of the reasons for the size difference of copper sulfides in AC and 8Cu1S samples.

Except for the factors discussed above, cooling history of sample also may have some effect on the formation of copper sulfide in steel. The cooling rate on solidification of the $8 \mathrm{Cu} 1 \mathrm{~S}$ sample is quite lower than that of the AC sample. Some MnS may precipitate on solidification, such as the MnS particles with large size in Fig. 9(a), and these MnS may lure copper sulfide to precipitate at higher temperature by acting as the nucleation site in the 8Cu1S sample.

In addition, the $\mathrm{Cu}$ and $\mathrm{S}$ concentration in the $8 \mathrm{Cu} 1 \mathrm{~S}$ sample are higher than those in the strip casting AC sample, in which they are 0.07 and $0.010 \%$ in mass, respectively. 

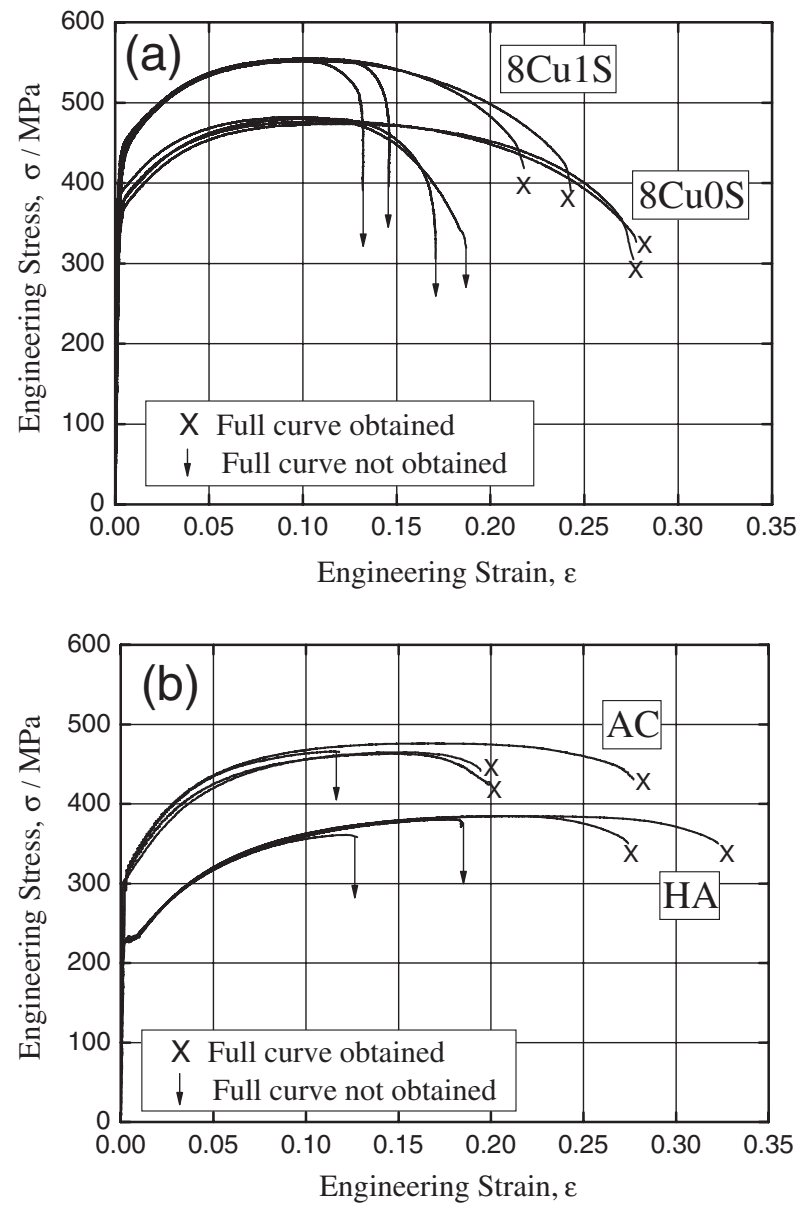

Fig. 12 Tensile stress-strain curves of (a) 8Cu1S and 8Cu0S samples and (b) AC and HA samples.

Therefore, the equilibrium precipitation temperature of copper sulfide in the $8 \mathrm{Cu} 1 \mathrm{~S}$ sample is higher than that in the AC sample.

Therefore, to obtain finer copper sulfide particles in steel, firstly it is important to suppress $\mathrm{MnS}$ precipitation on solidification or at a high temperature by using a high cooling rate and a composition design such as adding phosphorus. Secondly, it is also significant to decrease the copper sulfide precipitating temperature or to promote copper sulfide to precipitate from ferrite iron instead of from austenite iron by using a high cooling rate and a proper composition design that includes the solutes of $\mathrm{Cu}, \mathrm{S}, \mathrm{Mn}$ and $\mathrm{P}$.

\subsection{Mechanical properties of nano-scale copper sulfides dispersed steel and its strengthening mechanism}

The stress-strain curves and the tensile properties of the $8 \mathrm{Cu} 1 \mathrm{~S}$ and $8 \mathrm{Cu} 0 \mathrm{~S}$ as well as AC and HA samples are shown in Fig. 12 and Table 2, respectively. It is clear that the samples containing nano-scale copper sulfides $(8 \mathrm{Cu} 1 \mathrm{~S}$ and AC samples) have higher yield strength and tensile strength than the samples not containing nano-scale copper sulfides (8Cu0S and HA samples). Since AC and HA samples have different microstructure while $8 \mathrm{Cu} 0 \mathrm{~S}$ and $8 \mathrm{Cu} 1 \mathrm{~S}$ samples may have the similar as-cast structure, hereafter the discussion will mainly focus on $8 \mathrm{Cu} 0 \mathrm{~S}$ and $8 \mathrm{Cu} 1 \mathrm{~S}$ samples.

The yield strength (YS) and the tensile strength (TS) of the
Table 2 Tensile test properties of $8 \mathrm{Cu} 1 \mathrm{~S}$ and $8 \mathrm{Cu} 0 \mathrm{~S}$ samples.

\begin{tabular}{|c|c|c|c|c|c|c|}
\hline Sample & YS (MPa) & $\mathrm{TS}(\mathrm{MPa})$ & UE (\%) & TE (\%) & TS-YS & YS/TS \\
\hline 8Cu1S-1 & 445 & 555 & 10.4 & 23 & 110 & 0.8 \\
\hline $8 \mathrm{Cu} 1 \mathrm{~S}-2$ & 433 & & & & & \\
\hline 8Cu1S-3 & 440 & & & & & \\
\hline $8 \mathrm{Cu} 1 \mathrm{~S}-4$ & 425 & 552 & 10.4 & 25 & 127 & 0.77 \\
\hline 8Cu1S-mean & 436 & 553.5 & 10.4 & 24 & 118.5 & 0.79 \\
\hline $8 \mathrm{Cu} 0 \mathrm{~S}-1$ & 375 & & & & & \\
\hline $8 \mathrm{CuOS}-2$ & 387 & & & & & \\
\hline $8 \mathrm{CuOS}-3$ & 365 & 477 & 11.2 & 28 & 112 & 0.77 \\
\hline $8 \mathrm{CuOS}-4$ & 368 & 474 & 11.5 & 30 & 106 & 0.78 \\
\hline 8CuOS-mean & 374 & 475.5 & 11.4 & 29 & 109 & 0.775 \\
\hline
\end{tabular}

$8 \mathrm{Cu} 1 \mathrm{~S}$ sample are $436 \mathrm{MPa}$ and $554 \mathrm{MPa}$, respectively; and of the $8 \mathrm{Cu} 0 \mathrm{~S}$ sample are $374 \mathrm{MPa}$ and $476 \mathrm{MPa}$, respectively. The strengths of the $8 \mathrm{Cu} 1 \mathrm{~S}$ sample are higher than those of the $8 \mathrm{Cu} 0 \mathrm{~S}$ sample. The work hardening ability of steel has been known to decrease with increasing of the strength level. ${ }^{14)}$ However, the value of TS-YS is $119 \mathrm{MPa}$ for the $8 \mathrm{Cu} 1 \mathrm{~S}$ sample and $109 \mathrm{MPa}$ for the 8Cu0S sample, which means that although the $8 \mathrm{Cu} 1 \mathrm{~S}$ sample has a higher strength level, it has a slightly better strain hardening ability than the $8 \mathrm{Cu} 0 \mathrm{~S}$ sample.

The $8 \mathrm{Cu} 1 \mathrm{~S}$ sample also has a higher YS as well as a larger TS-YS than that of the $8 \mathrm{Cu} 0 \mathrm{~S}$. On the other hand, the total elongation (TE) and the uniform elongation (UE) of the $8 \mathrm{Cu} 1 \mathrm{~S}$ sample (24\% and $10.4 \%$, respectively) are only slightly lower than those of the $8 \mathrm{Cu} 0 \mathrm{~S}$ sample (29\% and $11.4 \%$, respectively).

Figure 13(a) shows the strain-hardening rate changes by the true strain in the $8 \mathrm{Cu} 1 \mathrm{~S}$ and $8 \mathrm{Cu} 0 \mathrm{~S}$ samples. The strainhardening rate in the $8 \mathrm{Cu} 1 \mathrm{~S}$ sample is slightly higher than that in the $8 \mathrm{Cu} 0 \mathrm{~S}$ sample for the entire true strain range, especially in the initial stage. Figure 13(b) shows that the $8 \mathrm{Cu} 1 \mathrm{~S}$ sample maintains good strain-hardening at a higher strength level compared to that of the $8 \mathrm{Cu} 0 \mathrm{~S}$ sample.

Table 2 shows that the difference in yield strength between the $8 \mathrm{Cu} 1 \mathrm{~S}$ and $8 \mathrm{Cu} 0 \mathrm{~S}$ samples is $62 \mathrm{MPa}$. The yield strength can be increased by one or more strengthening mechanisms such as solid solution strengthening, grain refining strengthening, and dispersion (or precipitation) strengthening, as described in eq. (2). ${ }^{15}$ )

$$
\begin{aligned}
\sigma_{y}=\sigma_{i} & +\sum_{1}^{j} k_{j} c_{j}+17.4 d^{-1 / 2} \\
& +\left(10.8 f^{1 / 2} / X\right)\left(\ln X / 6.125 * 10^{-4}\right)
\end{aligned}
$$

where $\sigma_{y}$ is the yield strength, $\sigma_{i}$ is the friction stress of iron, $c_{j}$ is the concentration of the $j$ th solute, $k_{j}$ is the strengthening coefficient of the $j$ th solute, $d$ is the grain diameter in $\mathrm{cm}, f$ is the volume fraction of second phase particles, and $X$ is the diameter of the second phase particles in $\mu \mathrm{m}$.

The solid solution strengthening in steel can be calculated as the following: ${ }^{16)}$

$$
\begin{aligned}
\sigma_{y}= & \sum_{1}^{j} C_{j}=4620 C_{C}+678 C_{P}+123 C_{S n} \\
& +83 C_{S i}+39 C_{C u}+32 C_{M n}
\end{aligned}
$$



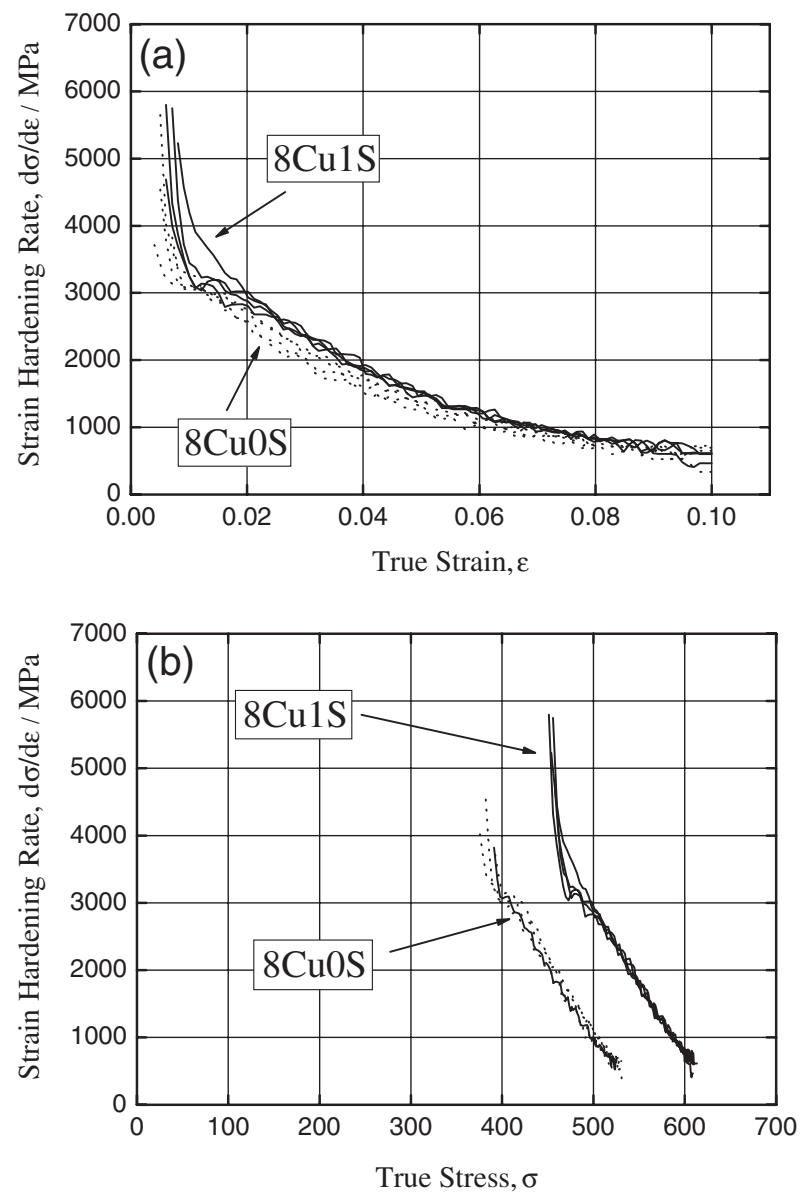

Fig. 13 Strain hardening rate $v s$. true strain (a) and true stress (b) curves of the $8 \mathrm{Cu} 1 \mathrm{~S}$ and $8 \mathrm{Cu} 0 \mathrm{~S}$ samples.

Table 3 The estimated contribution of grain size, solid solution and particles to the difference in the yield strength between the $8 \mathrm{Cu} 1 \mathrm{~S}$ and $8 \mathrm{Cu} 0 \mathrm{~S}$ samples.

\begin{tabular}{lcccc}
\hline \multicolumn{1}{c}{ Items } & Grain size & Solid solution & Particles & Total \\
\hline$\Delta \sigma_{y} / \mathrm{MPa}$ & 11.6 & 10.4 & 33.8 & 55.8 \\
$\Delta \sigma_{y} / \Delta \sigma_{y, \text { Total }}(\%)$ & 18.7 & 16.8 & 54.5 & 100 \\
\hline
\end{tabular}

Since $8 \mathrm{Cu} 1 \mathrm{~S}$ and $8 \mathrm{Cu} 0 \mathrm{~S}$ samples have similar structures, a same criterion such as eqs. (2) and (3) can be used to estimate the contribution of the solid solution strengthening, grain refining strengthening and second phase particle strengthening to the yield strength difference between the $8 \mathrm{Cu} 1 \mathrm{~S}$ and $8 \mathrm{Cu} 0 \mathrm{~S}$ samples.

Assuming that $80 \%$ of sulfur in steel precipitates as fine copper sulfides and $20 \%$ of sulfur as the solid solution element or the few large sulfide particles in the $8 \mathrm{Cu} 1 \mathrm{~S}$ sample, the YS difference due to the sulfide particles is about 33.8 MPa. The YS differences due to the solid solution and grain size are 10.4 and $11.6 \mathrm{MPa}$, respectively, according to eqs. (2) and (3). The calculation results are listed in Table 3.

The total YS difference due to the different solid solution strengthening, grain refining strengthening, and sulfide particle strengthening between $8 \mathrm{Cu} 0 \mathrm{~S}$ and $8 \mathrm{Cu} 1 \mathrm{~S}$ samples is about $55.8 \mathrm{MPa}$. This value is slightly less than the measured value of $62 \mathrm{MPa}$. One possible reason for this difference is that although the samples have uneven as-cast structures, eq. (2) was based on a uniform structure such as a structure after aging or deformation. ${ }^{17,18)}$ Refiner grains in such uneven structures may have higher strengthening roles compared to those in the uniform structure, which means that it may be better if the coefficients, such as 17.4 and 10.8, in eq. (2) are slightly enlarged when the samples have uneven as-cast structures.

Although it may be better to modify eqs. (2) and (3) to make it more suitable for samples with as-cast structures, we can conclude that most of the difference in the YS between the $8 \mathrm{Cu} 1 \mathrm{~S}$ and $8 \mathrm{Cu} 0 \mathrm{~S}$ samples results from the finer copper sulfide particles in the $8 \mathrm{Cu} 1 \mathrm{~S}$ sample. These particles are also necessary for the $8 \mathrm{Cu} 1 \mathrm{~S}$ sample to obtain good work hardening ability.

\section{Conclusions}

As-cast samples with and without copper sulfide, are prepared by the water cooled $\mathrm{Cu}$ mould casting process in the laboratory and strip casting process. The $\mathrm{Cu}$ mould casting process has a lower cooling rate on solidification and a higher cooling rate after solidification and then produces samples that have a solidification microstructure with a larger second dendrite arm spacing and a finer as-cast ferrite structure compared to that from the strip casting process.

Nano-scale copper sulfides of less than $50 \mathrm{~nm}$ are obtained from the as-cast sample that was produced by both rapid solidification processes. Three factors are important for obtaining the finer copper sulfide particles: (1) Suppressing the precipitation of $\mathrm{MnS}$ on solidification or at a high temperature by using a high cooling rate and a composition designing such as adding phosphorus to the steel. Such MnS precipitation will decrease the supersaturation when copper sulfide precipitates and will lure copper sulfide to precipitate at a higher temperature. (2) Decreasing the precipitating temperature of copper sulfide and increasing its supersaturation on precipitation by using a high cooling rate and a composition design with proper $\mathrm{Cu}, \mathrm{S}$, and $\mathrm{Mn}$ concentrations in steel. (3) Promoting copper sulfide to precipitate from alpha ferrite iron instead of from austenite by adding some element such as phosphorus which could change the phase transformation temperature.

A clear difference in the yield strength between samples with and without finer copper sulfides is observed. Solid solution strengthening, grain refining strengthening, and copper sulfide particles strengthening are responsible for to this difference, while finer copper sulfide particles is the main contributor to this difference. Finer copper sulfide particles also contribute to the finer structure and good work hardening ability of the sample at the higher strength level.

\section{Acknowledgements}

The authors would like to express their gratitude to Dr. F. Yin, NIMS, and Mr. N. Yoshida, Sumitomo Metals, for their fruitful discussions. The first author wishes to thank the Japan Society for the Promotion of Science for supporting his research work. 


\section{REFERENCES}

1) J. Syarif, T. Hoshino, T. Tsuchiyama and S. Takaki: Tetsu-to-Hagane 86 (2000) 558-562.

2) M. Charleux, F. Livet, F. Bleg, F. Louchet and Y. Brechet: Phlosophical Magazine A 73 (1996) 883-897.

3) S. W. Thompson and G. Krauss: Metall. Mater. Trans. 27A (1996) 1573-1588.

4) A. Guillet, E. Es-sadiqi, G. Lesperance and F. G. Hamel: ISIJ Int. 36 (1996) 1190-1198.

5) Z. Liu, Y. Kobayashi and K. Nagai: Mater. Trans. 45 (2004) 479-487.

6) K. Hirata, O. Umezawa and K. Nagai: Mater. Trans. 43 (2002) 305 310 .

7) A. Suzuki, T. Suzuki, Y. Nagaoka and Y. Iwata: J. Japan Inst. of Metals 32 (1968) 1301-1305.

8) N. Yoshida, O. Umezawa and K. Nagai: ISIJ Int. 43 (2003) 348-357.
9) Tekko-Binran (Handbook of Iron and Steel), 3rd Ed., (ISIJ, Maruzen, Tokyo, 1981) pp. 193-205.

10) F. Yin, A. Sakarai and K. Nagai: CAMP-ISIJ 17 (2004) 386-389.

11) Z. Liu, Y. Kobayashi and K. Nagai: Mater. Trans. 46 (2005) 26-33.

12) Z. Liu, Y. Kobayashi and K. Nagai: ISIJ Int. 44 (2004) 1560-1567.

13) Z. Liu, Y. Kobayashi, J. Yang, K. Nagai and M. Kuwabara: ISIJ Int. 46 (2006) 744-753.

14) W. B. Morrison: Ultrafine-Grain Metals, ed. by J. J. Burke and V. Weiss, (Syracuse Univ. Press, 1970) pp. 183.

15) T. Gladman: The Physical Metallurgy of Microalloyed Steels (For the Institute of Materials, 2002) pp. 46-57.

16) T. Gladman: The Physical Metallurgy of Microalloyed Steels (For the Institute of Materials, 2002) pp. 28-38.

17) E. O. Hall: Proc. Phys. Soc. 64B (1951) 747-753.

18) N. J. Petch: Jour. Iron Steel Inst. 174 (1953) 25-28. 